\title{
Become Tomorrow's Rehabilitation Researcher! Join the Rehabilitation Medicine Scientist Training Program
}

Where is the evidence base for rehabilitation treatments? How can we support the value of rehabilitation with payers and policy makers?

Rehabilitation research is the key, and well-trained rehabilitation researchers are needed for the job! We offer NIH-funded research training fellowships at competitive salaries to selected individuals to study with a nationally prominent mentor of their choice for up to 3 years. The goal of the program is to train a cohort of physiatric researchers - focusing on both adult and pediatric rehabilitation topics - who can compete successfully for NIH and other research funds, and who can contribute original research to the advancement of the field. PGY2 and PGY3 residents, and academic faculty members within 5 years of completing their training, are invited to attend a research training workshop held at the annual meeting of the Association of Academic Physiatrists, to help them prepare for the funded RMSTP fellowship. Applications for the research training workshop are due December 1, 2013. Applications for the NIH-funded fellowships are due September $1^{\text {st }}$ of each year. For more information and to apply on line, please visit the AAP website, www.physiatry.org, click on Rehabilitation Medicine Scientist Training Program (RMSTP) or contact the Program Coordinator for the RMSTP, Mary Czerniak, at meczerni@einstein.edu or (215) 663-6592.

The Journal of Pediatric Rehabilitation would like to recognize the following Pediatric Physiatrists who are part of the Rehabilitation Medicine Scientist Training Program:

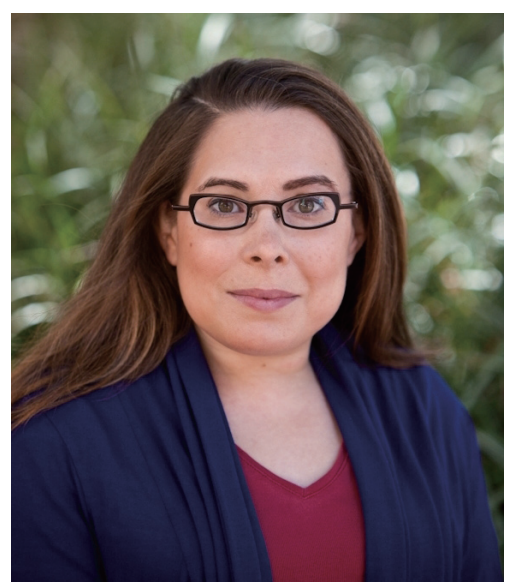

Amy Houtrow, MD, PhD, MPH

Dr. Houtrow obtained her MD from Michigan State University and subsequently completed residency training in a combined Pediatrics and Physical Medicine and Rehabilitation program at Cincinnati Children's Hospital Medical Center and the University of Cincinnati. During her residencies, she also completed an MPH in Health Policy and Management at the University of Michigan. From 2005-2012, she was Assistant Professor of Clinical Pediatrics at the University of California at San Francisco. While there she completed her $\mathrm{PhD}$ in medical sociology. She is now the Vice Chair for Pediatric Rehabilitation Medicine for the Department of Physical Medicine and Rehabilitation at the University of Pittsburgh. Her research focuses on understanding the family impacts of raising children with disabilities. 


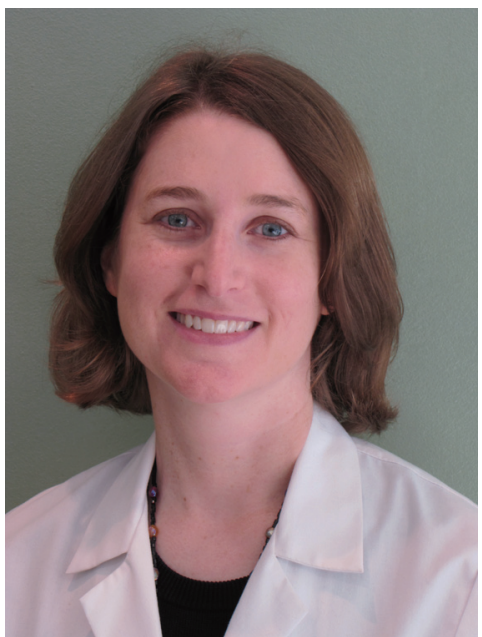

Stacy Suskauer, MD

Dr. Suskauer obtained her MD from Duke University and subsequently completed a combined Pediatrics and Physical Medicine and Rehabilitation residency program at Cincinnati Children's Hospital Medical Center and the University of Cincinnati. Her training continued with a Rehabilitation Research Fellowship at Kennedy Krieger Institute and Johns Hopkins University School of Medicine, where she is currently an Assistant Professor in the Departments of Physical Medicine and Rehabilitation and Pediatrics. Dr. Suskauer's research interests include the use of neuroimaging techniques and cognitive/behavioral evaluation to better understand deficits commonly observed following pediatric traumatic brain injury.

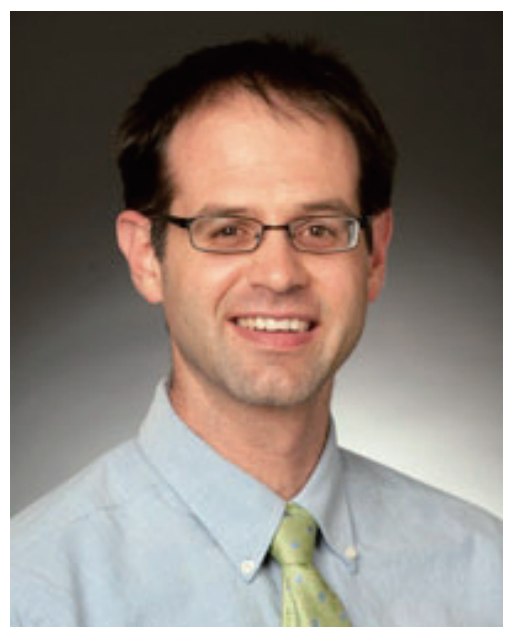

Brad Kurowski, MD

Dr. Kurowski completed his BS and MS in biochemistry and molecular biology at the University of Massachusetts, Amherst in 2000. He completed his medical school training at Case Western Reserve University School of Medicine in 2004. Subsequently, he completed his residency at the University of Pittsburgh Medical Center in 2008 and fellowship training in Pediatric Rehabilitation Medicine at Cincinnati Children's Hospital Medical Center in 2010. During his RMSTP training, he will be studying the relationship of genes and environment to recovery from pediatric traumatic brain injury under the guidance of his primary mentor, Dr. Shari Wade. He will be starting a faculty position at Cincinnati Children's Hospital Medical Center and will hold an academic appointment in the department of PM\&R at the University of Cincinnati School of Medicine. 